\title{
IMPLEMENTING DWECK'S GROWTH MINDSET BY INCORPORATING INDUSTRY BASED TOOLS AND TECHNIQUES IN THE CLASSROOM
}

\author{
Wilfred Mutale, Pittsburgh Technical College, mutale.wilfred@ptcollege.edu \\ Mel Tomeo, Pittsburgh Technical College, tomeo.mel@ptcollege.edu \\ John J. Scarpino, Pittsburgh Technical College, scarpino.john@ptcollege.edu \\ Cristina D'Imperio, Pittsburgh Technical College, dimperio.cristina@ptcollege.edu \\ Xihui Zhang, University of North Alabama,xzhang6@una.edu
}

\begin{abstract}
The impact of Information Technology (IT) tools is rapidly evolving and creating new technological innovations within society. Individuals in the IT field are required to have a "growth mindset" to stay up-to-date with these rapid changes in technology. This study was conducted at Pittsburgh Technical College located in Pennsylvania which incorporates industry trending technology tools in the classroom. The tools used in classrooms are designed to acquaint and prepare students for a career in IT with the hands-on, applied knowledge and techniques implemented in enterprise environments. This study outlines Dweck's growth mindset of students when incorporating industry based information technology tools in the classroom and the techniques implemented.
\end{abstract}

Keywords: Information Technology (IT), Classroom Techniques, Hands-on Learning, Growth Mindset, Industry Trending Technology Tools, Career Success, Workplace Skills

\section{INTRODUCTION}

This study investigates how the incorporation of industry based Information Technology (IT) tools in the classroom prepares students with a growth mindset for a career success in the workplace. According to Dweck (2013), a growth mindset is the belief that intelligence or talent can be developed through effort and determination. Students with a growth mindset are more motivated to learn, want to work harder, are less discouraged by difficulty, use more effective strategies for learning, and have higher academic performance (Cury, Elliott, Da Fonseca, \& Moller, 2006; Dweck \& Leggett, 1988). In addition, students with a growth mindset have an advantage in learning new technology tools used in the classroom over students with a fixed mindset. Research has shown that students who hold a growth mindset possess the grit to significantly improve grades and increase aptitude in learning (Aronson, Fried, \& Good, 2002).

In contrast to growth mindset, students with a fixed mindset believe that intelligence is a static trait; something that one is born with. Consequently, students with a fixed mindset avoid attempting new challenges for fear of failure and create an urgency of wanting to prove oneself over and over as being intelligent; hence they maintain a status quo (Dweck, 2006). In particular, students with a fixed mindset struggle to engage themselves with other students; they do not participate in class discussions, complete assignments, or regularly show up to class. Despite a number of early interventions to improve their motivation, too many capable students started out excited about IT or Computer Programming (CP), only became frustrated and finally withdrew from these programs. Most of these students had a fixed mindset (Edwards \& Li, 2016).

In recent years, our department has partnered with various software vendors in an effort to bridge the gap between corporations and higher education institutions. These vendors have allowed us to have access to their enterprise tools and utilize these tools for research and development. This study discusses some specific industry based software tools that we have incorporated in our curriculum. These technology tools are designed to get the job done efficiently with less cost. They are also designed to give students a firsthand learning experience in configuring, implementing, maintaining, and troubleshooting systems. Our department, School of Information Technology, has a 95\% placement rate of students who obtain internships that ultimately turn into full-time jobs. The shift in the demand for IT jobs requires that students seeking entry-level to intermediate-level jobs have proper education and skills in industry's trending technologies (Carnevale, Smith, \& Strohl, 2013). 
The success of students with a growth mindset in the School of Information Technology in securing internships that convert to full-time jobs has been largely due to their ability to persevere through rigorous courses that offer challenging enterprise level labs and assignments designed to prepare them with the knowledge and skills required in the workplace. Information Technology students with a growth mindset learn through hands-on or experimental implementation of new technology tools by working on challenging class projects, labs, and assignments that are designed to motivate them to apply techniques taught in the classroom and allow them to acquire the knowledge and skill set required in the industry (MicroTek, 2017). Research shows that pedagogies with increasing active experimental, hands-on learning have been effective in increasing students' engagement, stimulating critical thinking, and improving problem solving abilities and learning outcomes, and developing essential practical skills (Gentry, 1990).

\section{RELATED WORK AND PROGRAM BACKGROUNDS}

\section{Mindsets of Students}

Research evidence suggests that one of the best strategies for increasing students' perseverance and improving their academic success is by supporting them in the development of a growth mindset (Dweck, 2015). Students with a growth mindset typically work harder, engage in productive academic pursuits, and persevere to overcome the challenges encountered in the learning process. Conversely, students with a fixed mindset towards learning are more likely to withdraw from pursuing academic success and give up easily when they encounter some challenges (Edwards \& Li, 2016; Mangels et al., 2006).

In addition, research shows that there is a correlation between students who succeed in their academics to attending class, doing homework, participating in group discussion, and belonging to a student-lead study group (Froyd \& Simpson, 2008). One of the optimal ways to improving the academic performance and success of students with a growth mindset is to improve their academic activities (e.g., increasing their class attendance, their engagement in class or group projects, the amount of time dedicated to studying, their time in attending tutoring sessions, and the number of successfully completed assignment or labs) (Gentry, 1990). Students with a growth mindset learn to persevere through academic challenges. In addition, students with a growth mindset have grit or determination to succeed regardless of the setbacks as they set forth academic goals to attain (Dweck, 2006).

\section{Classroom Techniques}

Research found that students retain only $5 \%$ of material presented through lecture and $30 \%$ through demonstration, whereas hands-on participation can lead to about a $75 \%$ retention rate (MicroTek, 2017). Students typically engage in doing course assignments that include labs, projects, exams, group assignments, and research papers as part of their assessment to meet the course objectives and learning outcomes (i.e., competencies). Most students aim to succeed on academic tests. Yet, there is increasing evidence that the likelihood of their success is influenced not only by their actual ability, but also by their personal belief (e.g., a growth mindset) and educational goals that they attempt to achieve (Elliot \& Dweck, 2013). Students with a growth mindset will attempt to learn something new knowing that it will be rewarding in the long run (Mangels et al., 2006).

The techniques that are taught in the classroom align with a course's objectives and its student learning outcomes. Assessments are administered throughout each quarter, students are evaluated on meeting specific learning outcomes that are mapped to course competencies. Students with a growth mindset demonstrate knowledge, skills, and mastery of the tools. The tools in themselves do not dictate the course outcomes and meet specific learning objectives; they are by and large supplementary to the courses in our curriculum. Students with a growth mindset need to have the opportunity to articulate their thoughts to what the experience is involving, even though the instructor is monitoring the experience (Gentry, 1990).

Technological advancement in the classroom is shaping the way students learn in today's emerging educational models. Technology promotes the incorporation of adaptive, hands-on, flexible learning and the delivery of modern pedagogies (MicroTek, 2017). Teaching students with a growth mindset about the use of industry based tools by incorporating active experiential learning through projects, labs, field trips, seminars, and attending conferences enables the students to formulate their own logic and comprehension (Bonwell \& Eison, 1991). 


\section{Information Technology Competences}

- Competence Outcome 1 - Configure, troubleshoot, and administer client or network operating systems.

○ Tools Needed: VMware, MS Server 2012, 2016, Cisco Packet Tracer, and Ubuntu Linux

- Competence Outcome 2 - Plan, design, and develop a functional and secure network infrastructure.

○ Tools Needed: Visio, VMware, MS Server 2012, 2016, Cisco Packet Tracer, Ubuntu Linux, Pfsense, and AlienVault

- $\quad$ Competence Outcome 3 - Implement support models based on best practices.

- Tools Needed: MS Visio, Cisco Packet Tracer

- Competence Outcome 4 - Exhibit professional career growth and meet the industry expectations of Information Technology Network Administration.

- Tools Needed: Capstone, combination of all tools.

\section{Computer Programming Competences}

- Competence Outcome 1 - Create a web based mobile device applications using standard programming languages.

○ Tools Needed: MS Visual Studio, Android Studios, Unity Technologies

- Competence Outcome 2 - Develop and enhance problem solving skills as applied to software development.

○ Tools Needed: MS Visual Studio, Android Studios, MySQL, Unity Technologies

- Competence Outcome 3 - Develop software using the Object Oriented Programing principles; inheritance, polymorphism and encapsulation.

- Tools Needed: MS Visual Studio, Android Studios, Unity Technologies

- Competence Outcome 4 - Exhibit professional career growth and meet the industry expectations of Computer Programming students.

- Tools Needed: Capstone, combination of all tools.

The competence outcomes stated above indicate that students with a growth mindset in these programs would learn the use of tools that align with each competence, respectively. At the end of the quarter, students will demonstrate mastery of the tools and the skills required in workplace during their capstone courses when they get to put in practice the knowledge learned from $1^{\text {st }}$ quarter to $6^{\text {th }}$ quarter of their respective program.

\section{Demographic}

Table 1 shows a breakdown of the gender population of student enrollment from October 2016 to April 2018 in the Information Technology (IT) and Computer Programming programs at our college. Data from the table below indicate that both IT and CP programs are mostly pursued by male students. The huge disparity in gender ratio could be attributed to the negative perception of Information Technology and Computer Programming fields of study by female students.

Table 1. Program Student Enrollment

\begin{tabular}{|c|c|c|}
\hline \multirow{2}{*}{ Program } & Gender & Number of Students \\
\hline \multirow{2}{*}{ IT } & Male & 414 \\
\cline { 2 - 3 } & Female & 44 \\
\hline \multicolumn{3}{|c|}{ Total } \\
\hline \multirow{2}{*}{ CP } & Male & 458 \\
\cline { 2 - 3 } & Female & 101 \\
\hline \multicolumn{2}{|c|}{ Total } \\
\hline
\end{tabular}

Table 2 breaks down the age range in Information Technology and Computer Programming programs at our college. Based on data obtained from our college's admissions office, we concluded that the majority of the students were in the age range between 18 to 25 years old (i.e., traditional students). Data from the table below show that both 
Information Technology (IT) and Computer Programming (CP) programs at out college are predominantly enrolled by a relatively younger student population.

Table 2. Student Age Range

\begin{tabular}{|c|c|c|}
\hline Program & Age Range & Number of Students \\
\hline \multirow{2}{*}{ IT } & 18 to 25 & 341 \\
\cline { 2 - 3 } & 26 to 50 & 117 \\
\hline \multicolumn{3}{|c|}{ Total } \\
\hline \multirow{2}{*}{ CP } & 18 to 25 & 458 \\
\cline { 2 - 3 } & 26 to 50 & 87 \\
\hline \multicolumn{3}{|c|}{ Total } \\
\hline
\end{tabular}

\section{RESEARCH METHODOLOGY}

\section{Research Instruments}

In this study, a survey was conducted with 166 students, who were students pursuing an Associate degree in Information Technology (IT) or in Computer Programming (CP). The instruments used in the study were a series of survey questions that required a "yes" or "no" answer. Participants to the survey were sent a link through email to access the questionnaire between January 2018 and April 2018. The targeted participants were students who were in their $1^{\text {st }}$ quarter through to their $6^{\text {th }}$ quarter (i.e., freshmen - sophomores). Participants were instructed to carefully read detailed sets of instructions pertaining to the survey before taking the survey. Participants were expected to fully understand the purpose of the survey, and agree to the terms and conditions before proceeding to taking the survey.

The purpose of the survey was to collect data and analyze the results to establish a correlation between students' perception of the information technology tools incorporated in the classroom and the career success in the workplace, and the growth mindset techniques implemented to foster learning of the tools. Surveys and questionnaires are one of the most widely used research techniques because they provide precise estimates of the prevalence of variables of interest. Using surveys and questionnaires is a research technique that targets a particular population with designed questions to measure and collect data pertaining to a specific topic (Cobos Alvarado et al., 2016).

\section{Questionnaire Development}

The survey questionnaire was divided into three main categories. The first category was the student's opinion (i.e., growth mindset) on the use of industry tools incorporated in the classroom. The second category was the student's opinion on the career growth (i.e., career success). Career growth classes demonstrate to the student the work cycle (e.g., the interview process, working in industry, and advancing from one position to another in the workplace). The final category was the student's opinion on the growth mindset through experiential "hands-on" learning approaches and techniques of using technology tools incorporated in the classroom.

\section{Questionnaire Deployment}

Participants in the survey were informed about the research work that was being conducted and subjective responses were encouraged to reduce biasness on data. The participants were students with a growth mindset who were in their $1^{\text {st }}$ to $6^{\text {th }}$ quarter for Information Technology and $2^{\text {nd }}$ and $6^{\text {th }}$ quarter for Computer Programming. The invitation, as a first contact with the participants, explained the average time needed to complete the questionnaire. SurveyMonkey provided the header of the survey, and specified whether an individual question was intended to be taken by Computer Programming students or by Information Technology students or by students from both programs. Before the survey was distributed to the students, the questionnaire was thoroughly reviewed and tested for simplicity and technicality. Once the questionnaire had met the criterion set by our research team, we then deployed the survey to the students and sent out reminders to improve participation. 


\section{RESULTS}

This study found that the total number of students with a growth mindset pursuing an associate degree in Computer Programming (CP) who participated in the survey was 50, and the total number of students with a growth mindset pursuing an associate degree in Information Technology (IT) who participated in the survey was 116. Participants in the survey ranged from first quarter (i.e., first three months of enrollment) to sixth quarter (i.e., 18 months of enrollment) at the college. Table 3 shows a breakdown of the survey participants from each quarter and program of study.

Table 3. Breakdown of Responses

\begin{tabular}{|c|c|c|}
\hline Program & Current Quarter & Responses \\
\hline \multirow{4}{*}{ IT } & $1^{\text {st }}$ Quarter & 22 \\
\cline { 2 - 3 } & $2^{\text {nd }}$ Quarter & 17 \\
\cline { 2 - 3 } & $3^{\text {rd }}$ Quarter & 13 \\
\cline { 2 - 3 } & $4^{\text {th }}$ Quarter & 22 \\
\cline { 2 - 3 } & $5^{\text {th }}$ Quarter & 12 \\
\cline { 2 - 3 } & $6^{\text {th }}$ Quarter & 30 \\
\hline \multicolumn{2}{|c|}{ Total } \\
\hline \\
\hline \multirow{2}{*}{ CP } & $2^{\text {nd }}$ Quarter & 33 \\
\cline { 2 - 3 } & $6^{\text {th }}$ Quarter & 11 \\
\hline
\end{tabular}

Question 1 for both CP and IT students: Do you think a required Internship assists you in your career growth?
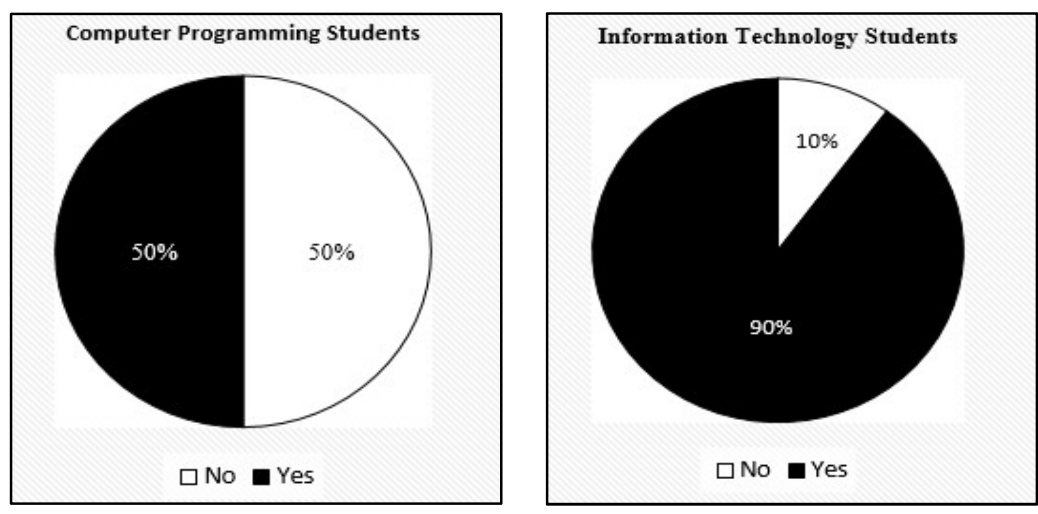

Data from the survey's Question 1 above indicate that 50\% of respondents from Computer Programming program with a growth mindset viewed that having a required internship program incorporated in the curriculum assists them with career growth (i.e., gaining knowledge and skills required in the workplace). In addition, $90 \%$ of respondents from Information Technology program with a growth mindset believe that having a required internship program incorporated in the curriculum assists them with career growth knowledge and skills required in the workplace. Internship at this college is a strict requirement for every student before graduation. Students are required to meet a total of 240 hours working on internship. The hours accrued on internship by students are mapped to the leadership course that is completed online to give an overview of their industry experience during internship. Data from the college's career services indicate that $66 \%$ of internships of students with a growth mindset in Information Technology program and Computer Programming program turn into full time jobs.

Question 2 for both CP and IT students: Do you think learning the four seminar courses (Steps to Career Success 1-3 and Career Development) assists you in your career growth? 


\section{Issues in Information Systems}

Volume 19, Issue 2, pp. 13-22, 2018
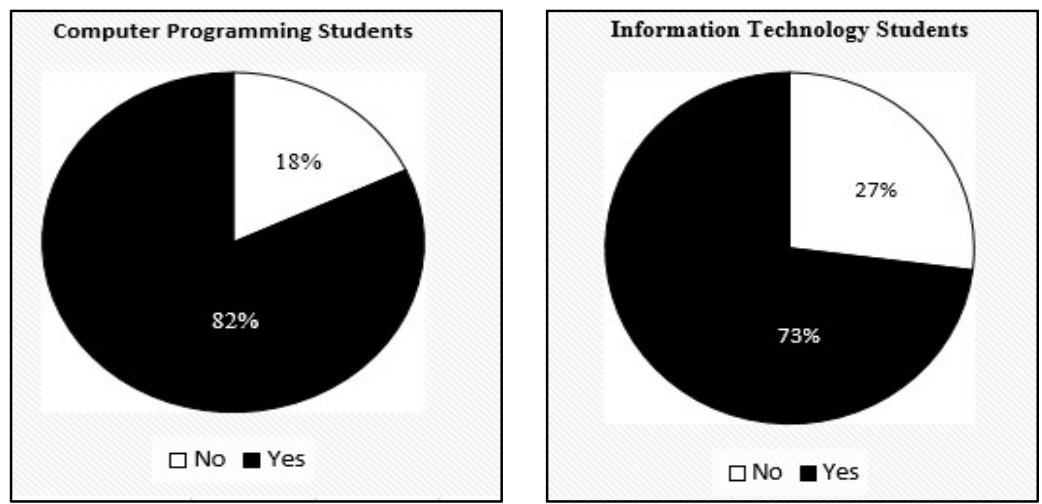

Based on data from Question 2 of the survey, $82 \%$ of survey respondents in Computer Programming program viewed seminars courses as being important for their career growth. On the other hand, the number of survey respondents in IT who viewed seminar courses as being important to their career growth was $73 \%$. Participants from both programs are required to take 3 seminar courses for one credit hour each as part of their program requirements. Seminar courses are designed to introduce students to "real world" workplace experience. Smeinar courses are fundamental to students with a growth mindset as they learning both soft and hard skills throught out each quarter (Froyd \& Simpson, 2008).

Question 3 for CP students only: Having classes which incorporate Microsoft Visual Studio provides you with the necessary knowledge for your career growth?

Question 3 for IT students only: Having classes which incorporate Windows Server provides you with the necessary hands-on knowledge required for your career success assistance for your career growth?
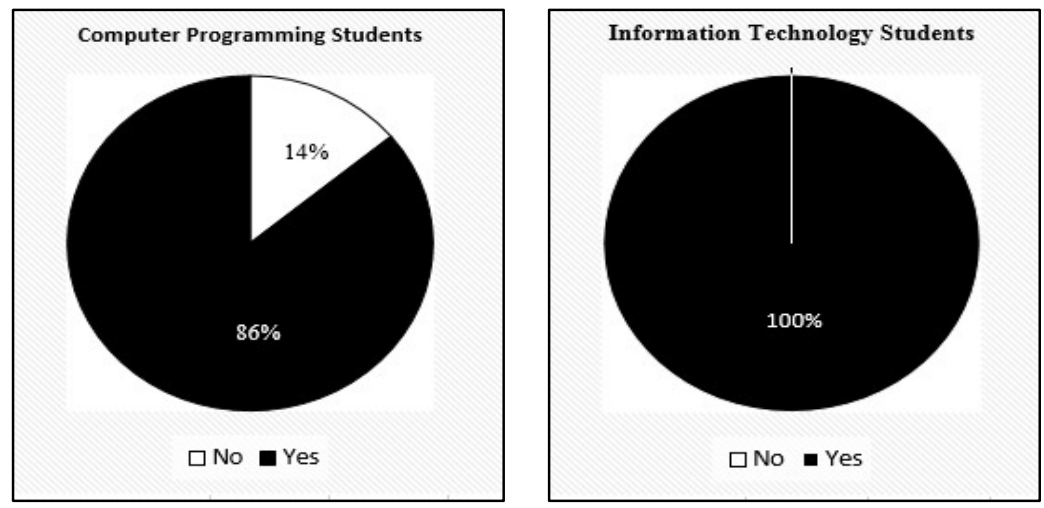

The study found that $86 \%$ of survey respondents for Computer Programming (CP) agree that having classes that use Microsoft Visual Studios is important in assisting with their career growth. While $100 \%$ of survey respondents in Information Technology (IT) believe that having classes that incorporate MS Windows Server as part of their learning provides them with assistance in their career growth. Data from each program's results indicate that students with a growth mindset at our college learn the use of information technology tools incorporated in the classroom through hands-on, applied, and active experimental learning. Students with a growth mindset like to be challenged to learn something new. 


\section{Issues in Information Systems}

Volume 19, Issue 2, pp. 13-22, 2018

Question 4 for CP students only: Having classes which incorporate Unity Technology provides assistance for your career growth?

Question 4 for IT students only: Having classes which incorporate VMware provides assistance for your career growth?
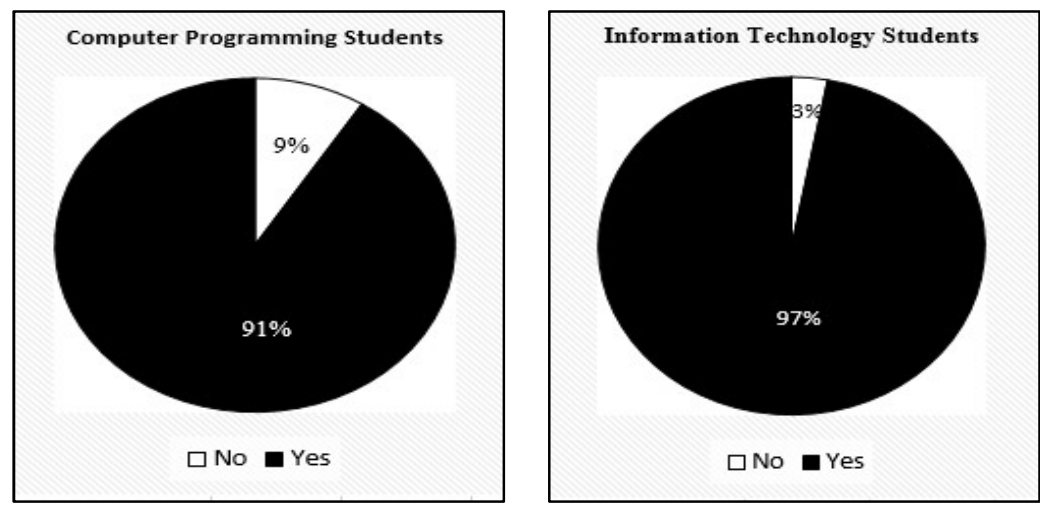

The survey data from students with a growth mindset indicate that $91 \%$ of respondents in Computer Programming program answered that having classes that incorporate Unity Technology as part of learning provides assistance to their career growth. Data from Information Technology survey respondents indicate that $97 \%$ of participants believe that having classes that incorporate VMware will provide them with assistance in their career growth. Computer Programming and Information Technology incorporate technology tools like Unity Technologies (only for CP) and VMware technologies (only for IT) in their curriculum. These tools are essential in teaching students fundamental skill sets that are required in enterprise work environments.

Question 5 for CP students only: Having classes which incorporate Android Studio provides for your career growth?

Question 5 for IT students only: Having classes which incorporate Packet Tracer provides assistance for your career growth?
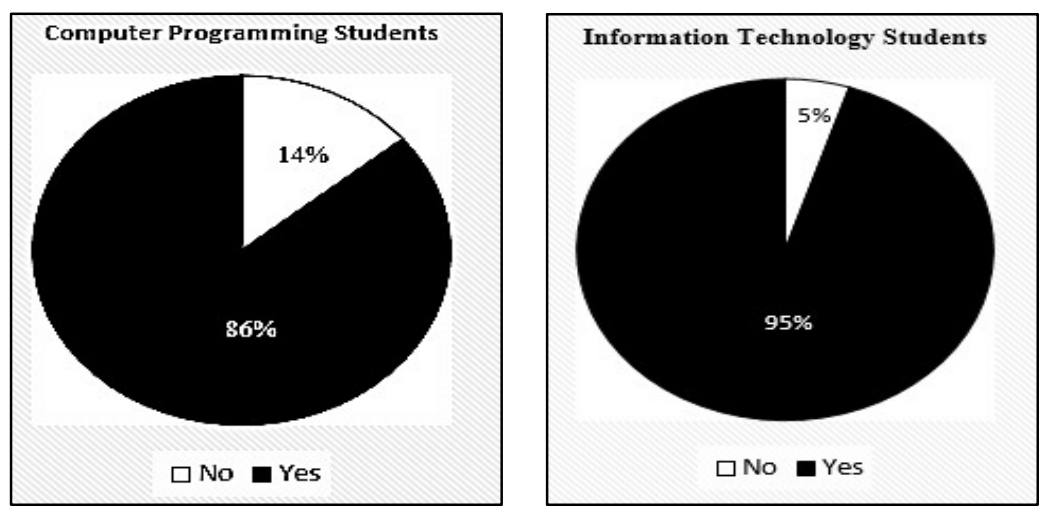

Data from the survey show that $86 \%$ of the respondents in Computer Programming program at our college answered that having classes that incorporates Android Studio as part of learning provides them with the assistance needed for their career growth. Android Studio is a platform used for mobile app development and plays a critical component towards the career success of students with a growth mindset. A total of $95 \%$ of survey respondents from Information Technology program answered that having a class that incorporates Cisco Packet Tracer provides assistance for their career growth. Cisco Packet Tracer is a network simulation tools that most IT students use to design and configure 


\section{Issues in Information Systems \\ Volume 19, Issue 2, pp. 13-22, 2018}

computer networks. We incorporate Cisco Packet Tracer to give our students with a growth mindset a hands-on learning in network administration.

Question 6 for CP students only: Having classes that incorporate MySQL provides assistance for your career growth?

Question 6 for IT students only: Having classes that incorporate Wireshark provides assistance for your career growth?
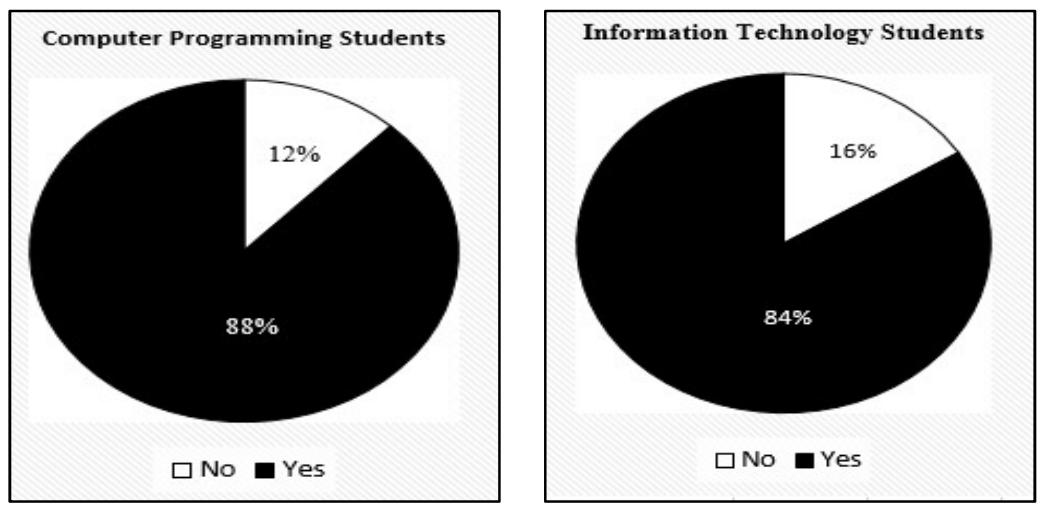

The study found that $88 \%$ of respondents from the survey in Computer Programming program answered yes to the incorporation of MySQL in their classes to provide assistance for their career growth. Students with a growth mindset are taught fundamental principles of MySQL and how it is implemented in a workplace. The techniques used in teaching students are incorporating labs, homework assignments, and work through with the instructor to get them comfortable. Comparably, 84\% of respondents from Information Technology program indicated that incorporating Wireshark as part of the learning process provides assistance to their career growth. Wireshark is a tool used in IT to monitor network traffic and also to investigate any network intrusion of foreign source and destination IP addresses.

Question 7 for both CP and IT students: Having classes which incorporate hands-on techniques provides assistance for your career growth?
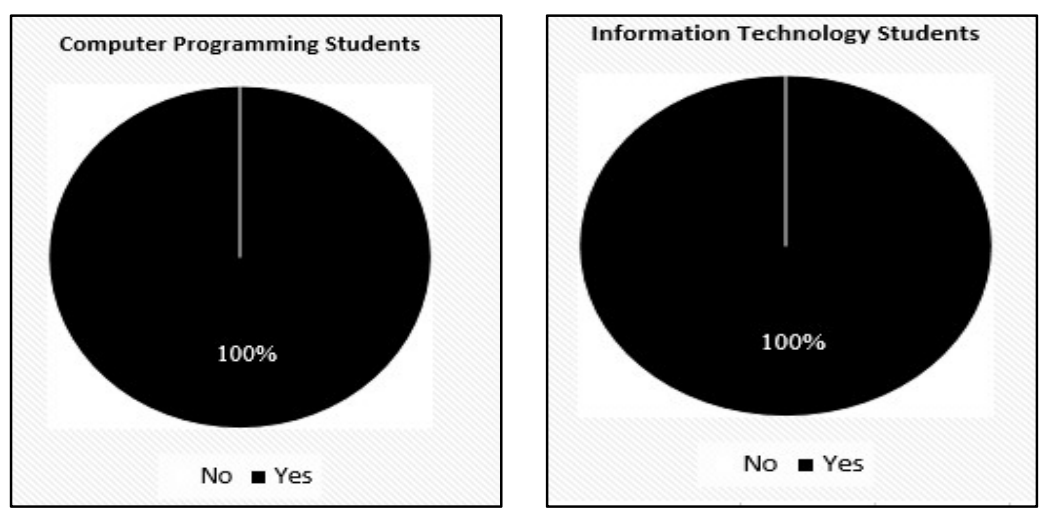

Data from the survey show that $100 \%$ of respondents from both programs answered that incorporating hands-on, applied, active experimental learning as part of the learning process provides the students with a growth mindset assistance with their career growth. In this study, our college motivates students to develop a growth mindset and encourage students to succeed in their academic pursuits. Research has shown that motivating students to have a growth mindset increases students retention of the knowledge and skills required to succeed in workplace (Dweck, 2015). 


\title{
DISCUSSION
}

\begin{abstract}
Summary of Content
This study focused on the students with a growth mindset in how they learn industry based technology tools utilized in modern IT workplaces. The tools are incorporated in our curriculum as supplementary, but integral part of the student's academic success. The tools in themselves do not dictate how the curriculum is developed and implemented as they are dynamic in nature. However, the tools are an ideal component in facilitating active experimental, handson learning. Students with a growth mindset and IT professionals alike can ease their pain of troubleshooting a complex system in a short amount of time with the proper use of industry based tools. In addition, the tools are designed to enable both the students with a growth mindset and IT professionals to get the job done efficiently and cost effectively. Students with a growth mindset are more likely to excel on a job that implements the tools that they have gains adequate hands-on experience in the classrooms during labs, projects, and assignments.
\end{abstract}

Students with a growth mindset played a key role in their motivation and achievement in pursuit of their studies. Students who believed their intelligence could be developed (i.e., a growth mindset) outperformed those who believed their intelligence was fixed (Dweck, 2015). Students with a growth mindset understand they can get smarter through hard work, the use of effective strategies, and help from others when needed. It is contrasted with a fixed mindset, which believes that intelligence is a fixed trait that is set in stone at birth. There is a correlation between students' growth mindset to academic success and career success in workplace (Elliot \& Dweck, 2013).

\section{Research Limitations}

The study did not investigate the shift in the student's mindset from a purely fixed mindset to that of a growth mindset and vice versa. Furthermore, the study did not explore other learning styles that would produce the same results as students with a growth mindset. Since the questionnaire is an explicit, self-report measurement, there might be some discrepancy between the responses that students entered on the survey instrument and the actual behavior in the classroom. The participants might have been unable to answer to questions based on their own belief about a tool (Cunningham, 2001). While the study aimed at analyzing the data that were collected from the survey taken by students with a grow mindset, the results indicates that some students had both a growth mindset and a fixed mindset (Dweck, 2013).

Another limitation of this study was how the mindset of instructors would impact the results. Instructors hold their own mindsets in their sphere of influence and when providing educational instructions on a subject matter. How would an instructor with a fixed mindset inspire students with a growth mindset? This dichotomy of mindsets was not investigated in our study. When educators become aware of the mindset of students, they are in a better position to create a classroom environment that foster the mindset that may increase students' motivation, effort, grit, and tenacity.

\section{Conclusion and Suggestions for Future Research}

In conclusion, our results indicate that students with a career growth mindset accept industry tools in their learning processes than students with a fixed mindset. This study aimed at understanding the correlation between students with a growth mindset learning Information Technology industry tools incorporated in our classroom to their career success in the workplace. Our findings highlighted the need to pay attention to the shift in the mindset of students. Additional research is needed to be done to determine whether the instructor's mindset influences the outcome of the students' mindsets. Instructors with a fixed mindset could negatively impact a student with a growth mindset. If formative assessment is on the rise, it is important to be aware that a growth mindset of students does not necessarily translate into more process-oriented feedback in the classroom. Further investigations are needed to examine the mindsets of students in a passive traditional lecture classroom environment to that of an applied, hands-on, and active experimental learning.

\section{REFERENCES}

Aronson, J., Fried, C., \& Good, C. (2002). Reducing the effects of stereotype threat on African American college students by shaping theories of intelligence. Journal of Experimental Social Psychology, 38(2), 113-125. 
Burgstahler, S. (2001). A collaborative model to promote career success for students with disabilities. Journal of Vocational Rehabilitation, $16(3$ \& 4), 209-215.

Bonwell, C. C., \& Eison, J. A. (1991). Active learning: Creating excitement in the classroom. 1991 ASHE-ERIC Higher Education Reports. Washington DC: George Washington University School of Education and Human Development.

Cobos Alvarado, F., Peñaherrera León, M., \& Ortiz Colon, A. M. (2016). Validation of a questionnaire on researchbased learning with engineering students. Journal of Technology and Science Education, 6(3), 219-233.

Cunningham, W. A., Preacher, K. J., \& Banaji, M. R. (2001). Implicit attitude measures: Consistency, stability, and convergent validity. Psychological Science, 12(2), 163-170.

Cury, F., Elliot, J., Da Fonseca, D., \& Moller, A. C. (2006). The social-cognitive model of achievement motivation and the 2 × 2 achievement goal framework. Journal of Personality and Social Psychology, 90(4), 666-679.

Carnevale, A. P., Smith, N., \& Strohl, J. (2013). Help wanted: Projections of jobs and education requirements through 2018. Washington DC: The Georgetown University Center on Education and the Workforce.

Dweck, C. S. (2006). Mindset: The new psychology of success. New York, NY: Ballantine Books.

Dweck, C. S., \& Leggett, E. L. (1988). A social-cognitive approach to motivation and personality. Psychological Review, 95(2), 256.

Dweck, C. S. (2013). Self-theories: Their role in motivation, personality, and development. London, UK: Psychology Press.

Dweck, C. S. (2015). Carol Dweck revisits the growth mindset. Education Week, 35(5), 20-24.

Edwards, S., \& Li, Z. (2016). Towards progress indicators for measuring student programming effort during solution development. Proceedings of the 16th Koli Calling International Conference on Computing Education Research (pp. 31-40). New York, NY: ACM.

Elliot, A. J., \& Dweck, C. S. (Eds.). (2013). Handbook of competence and motivation. New York, NY: Guilford Publications.

Froyd, J., \& Simpson, N. (2008). Student-centered learning addressing faculty questions about student-centered learning. Proceedings of the Course, Curriculum, Labor, and Improvement Conference (pp. 1-11), Washington DC.

Gentry, J. W. (1990). What is experiential learning. In J. W. Gentry (Ed.), Guide to business gaming and experiential learning (pp. 9-20). Dubuque, IA: Nichols Publishing Company.

Mangels, J. A., Butterfield, B., Lamb, J., Good, C., \& Dweck, C. S. (2006). Why do beliefs about intelligence influence learning success? A social cognitive neuroscience model. Social Cognitive and Affective Neuroscience, 1(2), 75-86.

MicroTek (2017). 7 benefits of incorporating hand-on-learning into your classroom training [Blog post]. Retrieved from https://blog.mclabs.com/7-benefits-of-incorporating-hands-on-learning-into-your-classroom-training 